This item was submitted to Loughborough's Research Repository by the author.

Items in Figshare are protected by copyright, with all rights reserved, unless otherwise indicated.

\title{
Offers of assistance in politician-constituent interaction
}

PLEASE CITE THE PUBLISHED VERSION

PUBLISHER

SAGE Publications

VERSION

AM (Accepted Manuscript)

PUBLISHER STATEMENT

This work is made available according to the conditions of the Creative Commons Attribution-NonCommercialNoDerivatives 4.0 International (CC BY-NC-ND 4.0) licence. Full details of this licence are available at: https://creativecommons.org/licenses/by-nc-nd/4.0/

\section{LICENCE}

CC BY-NC-ND 4.0

\section{REPOSITORY RECORD}

Hofstetter, Emily, and Elizabeth Stokoe. 2019. "Offers of Assistance in Politician-constituent Interaction". figshare. https://hdl.handle.net/2134/18110. 


\section{Offers of assistance in politician-constituent interaction}

Emily Hofstetter and Elizabeth Stokoe*

Department of Social Sciences

Loughborough University

Loughborough

LE11 3TU

UK

Tel: +44(0)1509 223360

Fax: +44(0)1509 223944

e.h.stokoe@lboro.ac.uk

Short title: Offers of assistance

Words: 10,888

Published in Discourse Studies, 2015, Vol. 17(6) 724-751; DOI: $10.1177 / 1461445615602376$

*To whom correspondence should be directed. 


\section{Biographies}

Emily Hofstetter is a PhD student in the Department of Social Sciences at Loughborough University, UK. She is currently studying how Members of Parliament interact with constituents at MP ‘surgeries' in the United Kingdom and Canada. Her research interests are in conversation analysis across both institutional and mundane settings.

Elizabeth Stokoe is Professor of Social Interaction in the Department of Social Sciences at Loughborough University, UK. Her current research interests are in conversation analysis, membership categorization, and social interaction in various ordinary and institutional settings, including neighbour mediation, police interrogation, role-play and simulated interaction. She is the co-author of Discourse and Identity (with Bethan Benwell, Edinburgh University Press, 2006) and co-editor of Conversation and Gender (with Susan Speer, Cambridge University Press, 2011). 


\section{Abstract}

How do politicians engage with and offer to assist their constituents; the people who vote them into power? We address the question by analyzing a corpus of 80 interactions recorded at the office of a Member of Parliament (MP) in the United Kingdom, and comprising telephone calls between constituents and the MP's clerical 'caseworkers' as well as face to face encounters with MPs in their fortnightly 'surgeries'. The data were transcribed, then analysed using conversation analysis, focusing on the design and placement of offers of assistance. We identified three types of offers within a longer 'offering' sequence: 1) 'proposal offers', which typically appear first in any offering sequence, in which politicians and caseworkers make proposals to help their constituents using formats that request permission to do so, or check that the constituent does indeed want help (e.g., "do you want me to”; “we could...”); 2) ‘announcement offers’, which appear second, and indicate that something has been decided and confirm the intention to act (e.g., "I will do X”), and 3) 'request offers', which appear third, and take for form "let me do X”. Request offers indicate that the offer is available but cannot be completed until the current conversation is closed; they also appear in environments in which the constituent reissues their problems and appears dissatisfied with the offers so far. The paper contributes to what we know about making offers in institutional settings, as well as shedding the first empirical light on the workings of the constituency office: the site of engagement between everyday members of the public and their elected representatives.

Keywords: Politicians, political discourse, constituency work, conversation analysis, offers. 


\section{Introduction}

How do politicians engage with and offer to assist their constituents; the people who vote them into power? The workings of constituency offices, in which members of the public have the opportunity to engage directly with their elected representatives, has received little to no empirical attention by interaction analysts or social scientists more generally. Yet it is in these settings that (where?) politicians engage with the everyday concerns of constituents. The current paper focuses on a key activity accomplished in such settings: responding to requests for help with offers of assistance. We focus first on previous interactional work on offers in other settings, before presenting our analysis of the way offers work in the constituency office. We will examine the contexts that elicit offers, and show how offers are built as one of a spectrum of possible ways to initiate action.

The constituency office

All MPs in the United Kingdom run constituency offices, usually fortnightly, which is a local bureau at which constituents can contact their local representative. The offices deal with a wide variety of issues, from social security and immigration, to neighbour disputes and development. The MP and their office staff ('caseworkers') assist by acting as mediators and ombudsmen, as well as referring constituents to other services. Caseworkers do the majority of the actual work of assisting constituents, and also take all the phone calls for the office.

There has been little research undertaken concerning the constituency office, and no one has studied what actually happens during surgery encounters. Constituency office casework is frequently investigated as a potentially effective method of campaigning and securing re-election (Yiannakis, 1981; Norton \& Wood, 1993; Butler \& Collins, 2001; Johnston \& Pattie, 2009). There is also work examining the motivations of politicians for 
engaging in casework (Fenno, 1978; Cain et al. 1987; Norris, 1992; Searing, 1994; Arter, 2010), given that it is uncertain whether casework does, in fact, lead to improved election results. Other studies examine whether and how constituencies influence politicians' actions at Parliament (Miller \& Stokes, 1963; Ågren et al., 2006; Blidook \& Kerby, 2011). A handful of studies examine the composition of casework (Rawlings, 1990; Macleod, 2006; Le Lidec, 2009). But none examine what happens when an MP and a constituent sit down to talk during constituency surgeries. This is surprising, given that researchers and politicians alike are interested in engaging voters in politics (see, for instance, the Hansard Audit of Political Engagement, 2015) and determining citizens’ political attitudes and beliefs (e.g., Dalton, 2000). This study is the first to open the 'black box' of what happens at constituency surgeries.

The constituency office, as an institution, may appear similar to doctors' surgeries; however, there are two major respects in which it differs. First, MPs are elected by their constituents, unlike doctors or any other service personnel. As a result, MPs are accountable for the actions to their constituents, and a constituent has the right to take anything the MP does or says as a motivation for giving the MP their vote (or not) in future elections. In other words, the MPs' job stability is partially in the hands of the constituents that visit the constituency office. There are other players to whom the MP is also accountable: the MP's political party (which provides funds for the MP to use in election campaigns, but which also requires the MP to vote 'in line' with party policies), and the 'selectorate' (the group of people who choose the MP as a candidate to run and represent a political party in the election). The party and selectorate want MPs to connect with local constituents, in recognition of the importance of constituents' opinions about the MP (Koop, 2012), but also require the MP to adhere to party policy, or else they will pick someone else. The MP must balance these contingencies when offering help to the constituents. 
Second, the role of the MP as a service provider is not as widely understood as a doctor's role. One sees a doctor in order to discuss problems with one's health, and to receive diagnoses, referrals and treatment. One sees an MP for all manner of social services, bureaucratic problems, and political discussion. Not only is the range of issues broader, but, as our data show, constituents do not know whether the MP will help at all, let alone what help is possible. There are no clear guidelines regarding what MPs should do to help constituents - in fact constituency service is not required of MPs at all (House of Commons Information Office, 2013), despite the fact that all MPs offer it. Although MPs are limited in their jurisdiction (for example, they cannot offer legal advice, nor intervene in local council issues), the MP in this data set regularly assisted constituents in matters that should have been council issues. Both the MP and caseworkers at this office reported that it is common practice for constituency offices to offer any help possible, shy of directly contradicting council authority. This furthers the uncertainty that constituents have over what is 'requestable', unlike the relative familiarity a patient has with what a doctor can provide. While a doctor is paid to treat and aid their patients, an MP is paid to legislate new laws, not to help constituents with their problems. Paired with the fact that any given constituent's vote is only one of the thousands of votes an MP needs, constituents express both uncertainty and low entitlement (Curl \& Drew, 2008) with respect to requesting aid. Despite the continuing increase in constituency casework that MPs offer and perceive to be necessary (see Norton \& Wood, 1993), there is not likewise a growing understanding of what MPs are for (Wright, 2010), especially in terms of casework.

At the constituency office, then, the institutional roles and norms are ephemeral in comparison to a doctor's office, which most people have experienced. This is not to say that there is not an institutional inferential framework permeating the context of the constituency office, but constituents' knowledge of the institutional context is limited. As a result, 
constituents have to learn the institutional rules as they go through the surgery meeting (cf. Pollner, 1979). The institutional 'rules’ are still talked into being (Drew \& Heritage, 1992), but much of the interactional work must be done by the institutional experts: the caseworkers and MP. This may be one context-related reason why we found that most surgeries are devoid of requests, as the constituent does not know what is requestable, and also why many of the offers of assistance are made multiple times, as the MP and caseworkers need to address (and even teach) what is institutionally appropriate for the constituency office. The constituents do not know what is requestable until they receive an offer; each offer that the MP and caseworkers make is also a way of habituating the constituents to what constituency offices are willing and able to do. As we will see in the analysis below, offers are regularly reissued during surgery meetings, and the format of the offers progresses the offered aid towards a state of acceptance.

\section{Offers}

Offers are, intuitively at least, the bedrock activity of service provision and other institutional settings, such as call centres or doctors' offices, as well as a regular activity in everyday social life. They can include concrete transactions, such as asking, 'Milk? Sugar?' when offering tea (Kärkkäinen \& Keisanen, 2012), as well as more intangible commitments to future action such as asking, 'Do you want help with your homework?' (Curl, 2006; Davidson, 1984). They may be made to fulfil another's need or desire, but they also may occur in the absence of any expressed need (Curl, 2006). But while they are a ubiquitous conversational action, offers can be difficult to define empirically. Conversation analysis, being an inductive process, has an ambiguous relationship with definitions. The Oxford English Dictionary provides the following definition of an offer: “An expression of readiness to do or give something if desired.” The verb, ‘to offer', is defined as "providing” or 
"presenting” something, “expressing readiness” to do something, and "to present or proffer something for someone to accept or reject as desired”.

Unsurprisingly, however, the OED definition is not entirely aligned with what participants in actual conversation treat as an offer. Offers take a variety of formats in a variety of contexts, making them difficult to disaggregate from 'invitations', 'proposals', or ‘suggestions'. Even 'requests', which Kendrick and Drew (2014) point out have been regarded as the 'opposite’ of offers, can potentially be interpreted as doing precisely such an action (see Extracts 15 and 16 below). In her own work on offers, Curl (2006: 1258) does not define what an offer is, but provides a statement to specify the general action under investigation as one which satisfies “some want or need of the recipient's, or propos[es] to assist in the resolution of a difficulty or misfortune experienced by the recipient”. Somewhat earlier, Maynard (1986: 268) argued that “parallel and consistent displays of alignment” constitute offers, in that they are done for the benefit of another person and made complete by recipient acceptance or rejection. Others have challenged the notion that offers are contingent on the recipient's acceptance or rejection, however; Toerien et al (2011) show how doctors use offers to circumvent patients' ability to reject or resist treatment options. This suggests that offers remain more contingent on the beneficial nature of the transaction, rather than the recipient's response.

In a recent paper, Couper-Kuhlen (2014) examined initiating actions that bring about, or aim to bring about, potential future courses of action, including offers. As a typology, such initiating actions prefer an accepting or aligning response; index regularly and negotiate issues of deontic and epistemic stance, and are geared towards making a future state exist (Couper-Kuhlen, 2014: 624). Offers are specifically defined as having the 'Self' as an agent (i.e., the offerer does the action required to bring about the future state), and the 'Other' as beneficiary (i.e., the recipient gets the object or assistance committed by the offerer), whereas 
requests work in the opposite direction (Couper-Kuhlen, 2014, p.628). However, the question of who benefits from an offer, and who suffers the costs, depends significantly on what the participants consider to be a benefit or a cost. Costs and benefits are not necessarily split such that one party benefits entirely and one party entirely is at cost. From a psychological perspective, when speakers make offers they place recipients in their debt (or at least earn their gratitude), which is a benefit to the speaker that could entirely outweigh any potential 'cost'. Further, an anthropologist might note that offering (and gift-giving, see Mauss, 1950 [1990]) is fundamental to cementing relationships and even inter-group treaties, and thus any 'cost' of offering is obscured by the potential benefits.

This difficulty in attributing costs and benefits can be seen in the extract below from the Holt collection. Lesley is having a package delivered to Philip, but the delivery company failed to charge Lesley for carriage costs. As it is a gift, she requests that he tell the company to charge her.

\section{Extract 1: Holt: X(Christmas)1:1:3, from Curl (2006)}

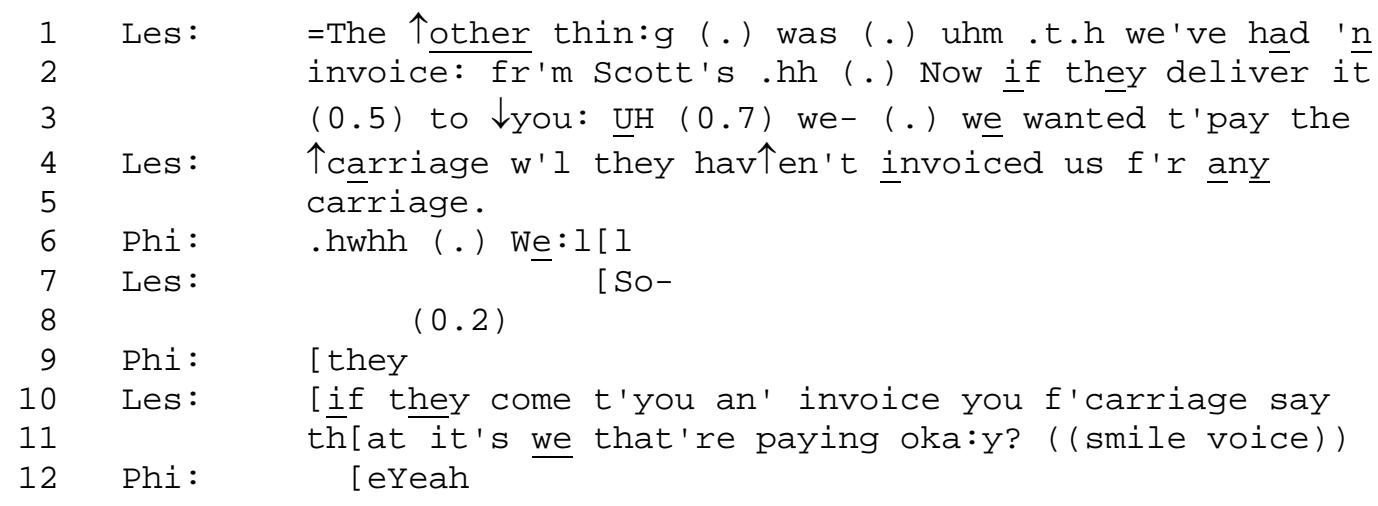

While Lesley’s 'request' benefits Philip - he will not have to pay for delivery of the package, it also benefits Lesley - she can maintain her status as gift-giver and fulfil her goal ("we wanted to pay the carriage”). The same dilemma is found in the politician-constituent data. In Extract 2, the MP's caseworker (CW) is speaking to a constituent (C), and requests to use information that the constituent explained earlier in the call. 


\section{Extract 2: MP01.Phone-13KK_03: 109-116}

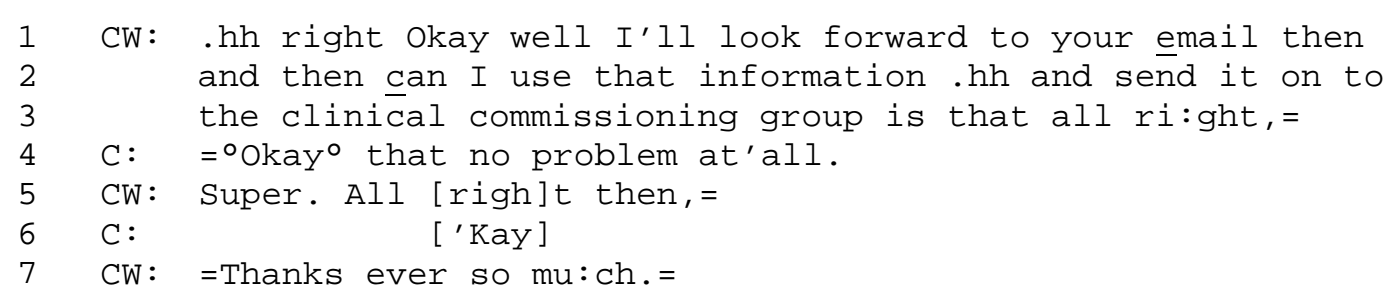

The caseworker's request (lines 2-3) benefits the caseworker, in that she can now fulfil her offer of assistance, but ultimately benefits the constituent, who will receive the assistance he requires. Who is the beneficiary in these instances? Are these requests or offers or something else? Couper-Kuhlen (2014) uses the term 'Proposals' to refer to these shared cost-benefit situations, but whether or not 'proposal' correctly characterizes the activities of Extracts 1 and 2 is moot. Furthermore, in neither extract are there clearly definable costs, only possible shared benefits. The cost/benefit possibilities are too variable for these categories.

Clayman and Heritage’s (2014) concept of a 'benefactive’ stance (and status) helps analysts navigate the question of what is beneficial. They introduce this idea with the same conundrum: "it may not always be the case that the offer recipient will treat the thing offered as a benefit” (p.4). In the same way that 'epistemic stance' describes how a turn configures distributions of knowledge, 'benefactive stance' refers to how talk distributes costs and benefits, as interlocutors see them. Benefactive status is "a complex of underlying conditions for the action, including such matters as whether a service will be rendered that is of actual benefit to its recipient, whether the performer of the service is able and willing to perform it...” (p.5). However, the concept relies on the possibility of objectively identifying 'actual' costs and benefits, whereas in many cases, including the ones above, it is not explicit. That said, benefactive stance provides a way of looking at the range of offers, requests, invitations, and other future projecting initiating actions. These actions have long been considered as part of a similar group (cf. Couper-Kuhlen, 2014), but also as discrete ‘objects’ (see Davidson, 
1984). But it may be more helpful to conceptualize these actions as a spectrum of options for initiating actions and transactions. Sacks wrote:

“We think of an 'offer' as something different than a 'request' or a 'warning' or a 'threat'. But in some situations the offer is simply the first version of getting the person to do something. ... One wants then to reconsider these objects - offer, request, warning, threat - not as though they're a series of different things, but to see them as sequential versions of a something” (1992, p.331).

As Couper-Kuhlen (2014) suggests, requests, offers, invitations, proposals, suggestions, warnings, etc., all share the goal of negotiating the creation of a future action, with two axes of variation (the degree of interlocutor agency, and the eventual distribution of benefits between them). While Couper-Kuhlen and Clayman and Heritage suggest an interpretation based on 'actual' costs and benefits, Sacks' suggestion leads to a more flexible interpretation, based on what the participants wish to achieve by doing the action (e.g., appear agentive, intimidate, cajole, hint, welcome). These additional goals will continue to confound our interpretation of action ascription unless we allow for actions such as requests and offers to be conceptualized as zones on a spectrum of possible actions, with grey areas between possibilities. This is because, as Stokoe (2012) points out, it is not the job of analysts to be more specific about designedly ambiguous descriptions and actions, than members themselves are. The fact that we cannot be definitive about what an action 'is' is what gives language practices their defeasibility (see Edwards, 2005).

Based on the offers in our dataset, we have defined offers as actions that indicate a future action for the benefit of the recipient, even if other benefits arise, which is at least mostly enacted by the speaker. Importantly, we argue that offers should be considered along a spectrum of actions that include proposals, announcements, invitations, and suggestions. 
The grey areas between prototypical examples should be seen as zones in which some additional work is being done by the turn in question, rather than as an invalidation of the offering aspects of the turn.

\section{Data and method}

The data comprises 80 recorded face-to-face and telephone interactions at the office of a Member of Parliament (MP) in the United Kingdom. The recorded data were transcribed using Jefferson's (2004) system for conversation analysis (CA), and the transcripts analysed using CA.

The data was trawled for all possible 'offers' of assistance and 250 instances were identified. Most fall into Curl’s (2006) category of “offers that are responsive to overt problems” (p.1270-1275). Unsurprisingly, we found no examples of offers as a reason-forcalling; in almost all calls, constituents are calling to receive, not make, offers of assistance. There are also no examples of what Curl calls 'educed-problem' offers, in which an offer is made distally to the original discussion of the problem (typically in a closing section), and the offer is made based on some item the speaker has educed to be a problem. This is also unsurprising, as constituents contact constituency offices because they have a problem, and their problem is therefore discussed explicitly. All of the MP or caseworker offers are, therefore, made in response to overt problems. Of course, the constituents would not be at (or calling) the office if they did not have some need of assistance meaning that any item that they bring forward is likely to be interpreted as potential item needing assistance. So while all of our offers fit into Curl's (2006) 'responsive to overt problems' category, we still encounter a dilemma: they do not all match the offer format or style as described in Curl, even allowing for the variety of formats she identified. For example, her participants never used a 'do you 
want' format in these types of offers. As we will see in the analysis, this does not hold true for offers at the constituency office.

\section{Analysis}

The analysis below is divided into four sections. The first focuses on 'proposal offers' ("Can I do X?”; “do you want me to do X?”), which we found to be the format for first offers of a certain course of action following a problem presentation from a constituent. The second section focuses on 'next offers', differentiating between offering a potential course of action, and explaining a potential course of action. The third section focuses on 'announcement offers' (“I will do X”), and the final on 'request offers' (“Let me do X”). In each section, we consider the interactional and institutional affordances of these different offer designs.

\section{First offers: Proposals}

Many offers made at the constituency office are made in a similar form to a proposal. These offers are characterized by a low degree of 'deontic force', in that they are formulated to require the permission or acceptance of the constituent before being enacted. They regularly use phrases such as “can I do X” or "do you want me to X”. In using the word 'proposal', we are attempting to capture aspects of the utterances, such as their deontic and epistemic stance and are not using it in the specific way that Couper-Kuhlen (2014) has used it to refer to a potential future action from which both parties benefit and for which both parties contribute to actuation. Our usage is closer to that of Stevanovic and Peräkylä (2012), to refer to a commitment to a potential future joint action that was contingent on the approval of the interlocutor. In this analysis, the term 'proposal' indicates an utterance that offers a potential future action of assistance, seeks the approval of the constituent before commencing action on the offer. 
Proposal-offers are exclusively used as the first offer of a certain course of action to a constituent. 'First' does not necessarily refer to the temporally 'first offer in an interaction' but to the first offer of any assisting action that occurs following a first presentation of a problem. For example, in the following call, the caseworker has called the constituent's house to give an update on a roof leak that the housing association is supposed to fix, but has not. Thus the call does not start with a first presentation of a problem, because the caseworker and constituent have previous discussed the roof problem. The first offer in the phone call is an 'announcement offer' regarding the update ('I'll go back to (.) John [to] ... explain to him that the scaffolding's been up three weeks” - see Announcement offers, below). Immediately following the temporally first offer, however, the constituent (C) introduces a new problem and a new sequence about which he has not spoken before. As part of this new sequence dealing with the new problem, the caseworker (CW) gives a 'proposal' offer, which is first with respect to the problem in question.

\section{Extract 3 - MP01.Phone-13KK_08: 107-116}

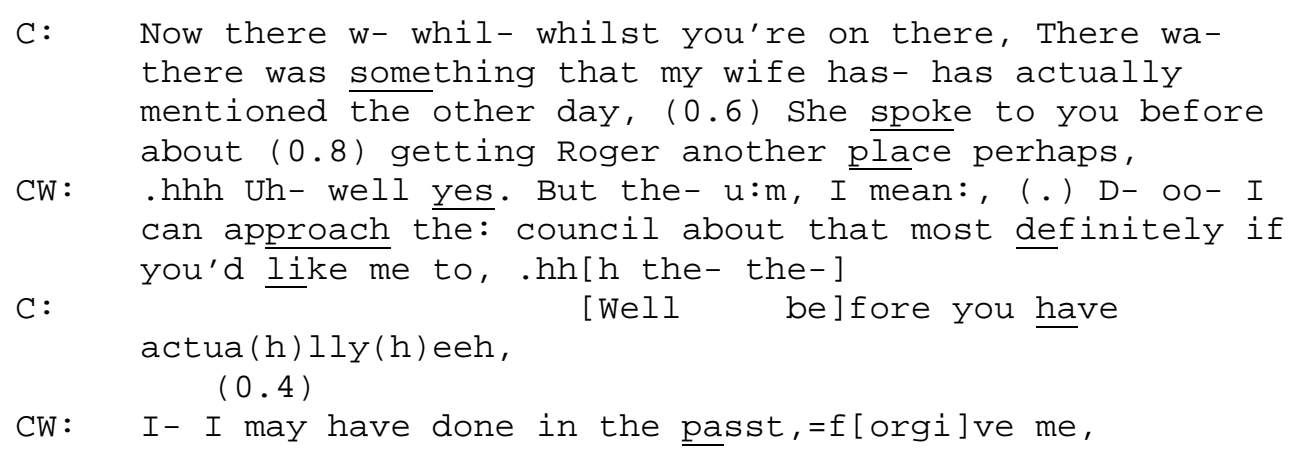

We found that the first offers for a course of action were routinely formatted as proposals, throughout the data. On lines 5-6 CW makes a new first 'proposal offer' to "approach the council” using the "I can” format. Note that is CW's belief that the offer has not already been 
made - which is corrected by C at lines 8-9 - that accounts for this possibly second offer being produced as a first.

Let us look at other instances of proposal-style offers. In Extract 4, C has been describing a threatening letter from her ex-partner in the context of child custody issues. At line 14, CW makes an offer based on a complaint that happened earlier in the call - that the Child Support Agency has not been in contact.

\section{Extract 4 - MP01.Phone-13KK_05: 216-234}

1 CW: So it was hand written,

2 C: Oh yes. This one was typed,

3 CW: $\uparrow$ Yeah.

4 C: From him.

$5 \quad(0.6)$

6 CW: Right.

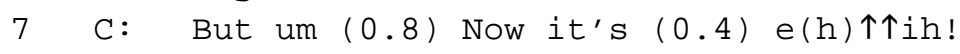

$8 \quad(1.7)$

9 CW: Oh: dear,

$10 \quad(0.3)$

11 C: ${ }^{\circ}$ Anyway, ${ }^{\circ}$

$12 \quad(0.6)$

$13 \mathrm{CW}$ : .hhH so Cee Ess Ay though, haven't contacted ya since last

14 Thursday, Can I chase them for you? $S^{\prime}$ that all right?=

$15 \mathrm{C}$ : $=\overline{<I^{\prime} \mathrm{d}}$ love you to cos with my phone not bei:ng $\overline{(0.4)}$ you know,

16 reliable,

17 CW: Yeah,

$18(0.4)$

19 C: U:m (0.5) <That would be fabulous.>

The caseworker's offer is formatted using what we observed to be the routine "can I" format for first offers, with a tag question (“s’that all right?”). These design choices index a low deontic stance; that is, CW displays that she is not yet certain that this will be an acceptable course of action for $\mathrm{C}$, and gives them the opportunity to raise concerns with this particular offer of assistance. However, C gives the preferred response, an acceptance, at line 19.

Note, however, that the offer takes place several minutes after the original problem was formulated. Curl (2006) referred to such offers as ‘educed’, appearing “... at some point which is temporally and sequentially distanced from the problem” (p.1265). We stated previously that there are no educed problems in our data; this is because the second half of 
Curl's definition: "Before the offer is made, the problem it educes is not treated by either participant as something in need of remedy” (p.1265). In Extract 4, the CSA issue was treated as a problem, but CW's offer was displaced by an inserted sequence about the threatening letter, which then took up the majority of the call. Once dealt with, CW returned to the original topic of the call, and made the offer accordingly. As a first offer, it was formatted as a proposal, in which CW seeks confirmation of the appropriateness of her proposed course of action (“Can I chase them for you? S'that all right?=”).

Extract 5 provides another example of proposal-offers. It is from the face-to-face surgery, in which the MP and a caseworker are talking to two constituents about the repatriation of an ill family member to a nursing home in the UK. Some contact has already occurred between the office staff (CW and MP) and the constituents (C and C2), especially over email. At this moment, $\mathrm{C}$ is inquiring about where her family member could stay while being assessed for long-term care.

\section{Extract 5 - MP01.Surgery-13KO_06: 469-487}

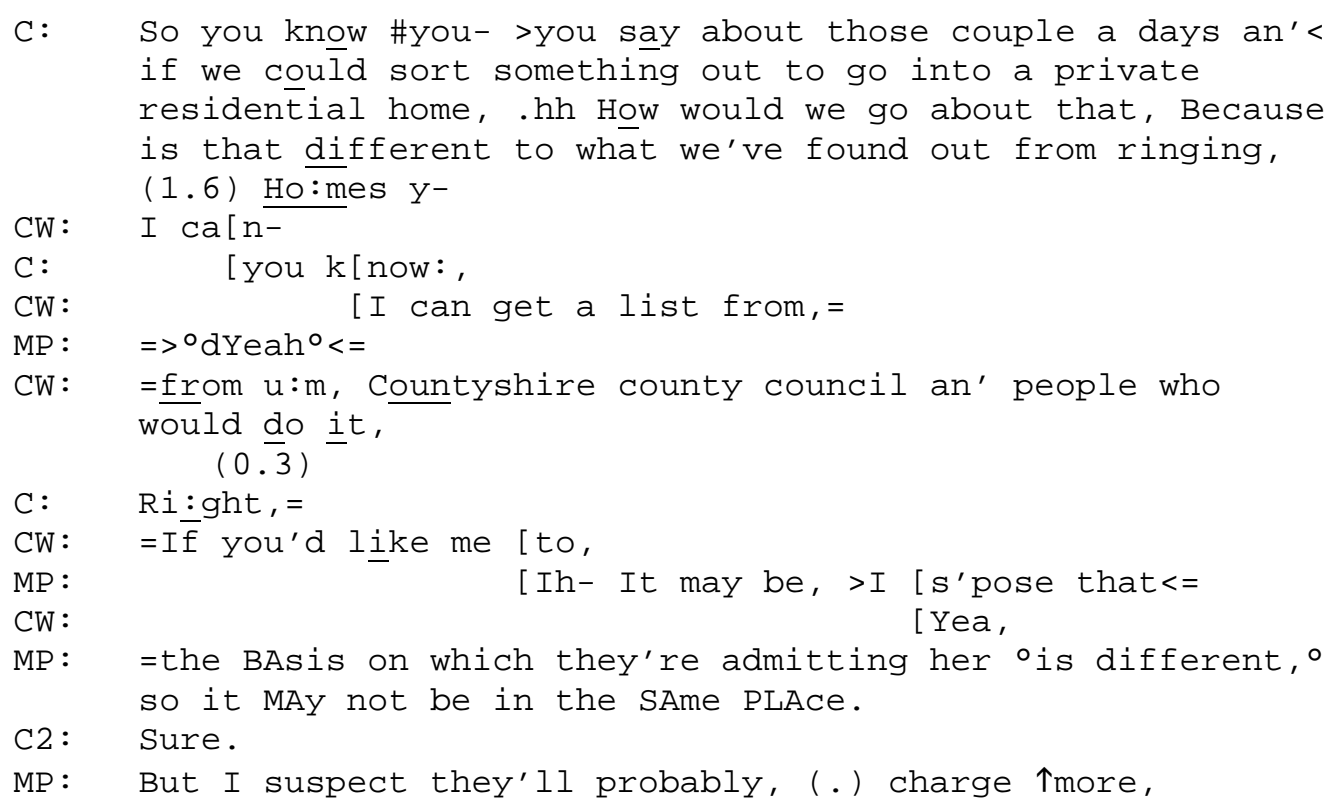

CW issues the offer on lines 5-10, the first to propose finding a list of short-term nursing home placements. The offer is phrased as a proposed, not definite, course of action, indicated 
by the verb 'can' (instead of 'I will'). This is further indicated by the increment added on line 13, "If you'd like me to", which emphasizes that this course of action would only be pursued 'if' the constituent approved. Such "I can do X” utterances could be treated as grammatical statements of information, informing recipients that speakers are able to do that action. In the context of a service setting, though, where offers of assistance are a core activity, "I can..." utterances convey courses of action that are possible. In particular, at constituency offices, where constituents need careful direction as to what aid is available, this design helps indicate what the constituency office staff are able and willing to do. The design presents the course of action as a potential future, to be assessed for viability and acceptability on the part of the constituent.

There is more evidence in Extract 5 that shows that and how "I can do X" utterances are offers (as opposed to 'merely' proposals, or commitments, etc.), making assessments or acceptances/rejections relevant. After making the offer in lines 7-10 ("I can get a list from...”), C’s response is slightly delayed (line 12) and neither accepts nor rejects the offer, but treats it as information (“Ri:ght”, line 13). At this point, then, C is not yet unambiguously oriented to CW's turn as an offer (although it is possibly on the way to being an offer). As a result, CW adds the increment "If you'd like me to," (line 14). This increment emphasizes that this action is an offer, and is for the benefit of the constituents, and that it will only be enacted if they desire. As Stevanovic and Peräkylä (2012) point out, this indexes greater rights on the part of the constituent to have a say in how their case is managed and what courses of action are pursued.

By indicating that the offer is contingent on the constituent's approval, the staff a) make clear what courses of action the constituency office staff can pursue on behalf of the constituent, and b) treat constituents as having greater epistemic and deontic rights over their own cases: they know all the details whereas staff only know what has been divulged so far. 
If constituents have already tried certain solutions, it is not useful to try them again. For example, in Extract 6, we return to the same call as Extract 5. C has been trying to get into state supported housing, and one way this process works in the United Kingdom is by bidding on houses, but she was unable to bid within the correct time period. Prior to the extract, $\mathrm{C}$ asked if there was new information on the house - information that $\mathrm{CW}$ was supposed to track down. However, CW had not found any new information, and so has to report her problematic failure to do so. Given that CW needs to help maintain good relationships with constituents, any perceived failure is a problem to be remedied, and as in the case below, CW usually follows any lack of success in accomplishing aid with a new offer of assistance.

\section{Extract 6-MP01.Phone-14AH_03: 20-53}

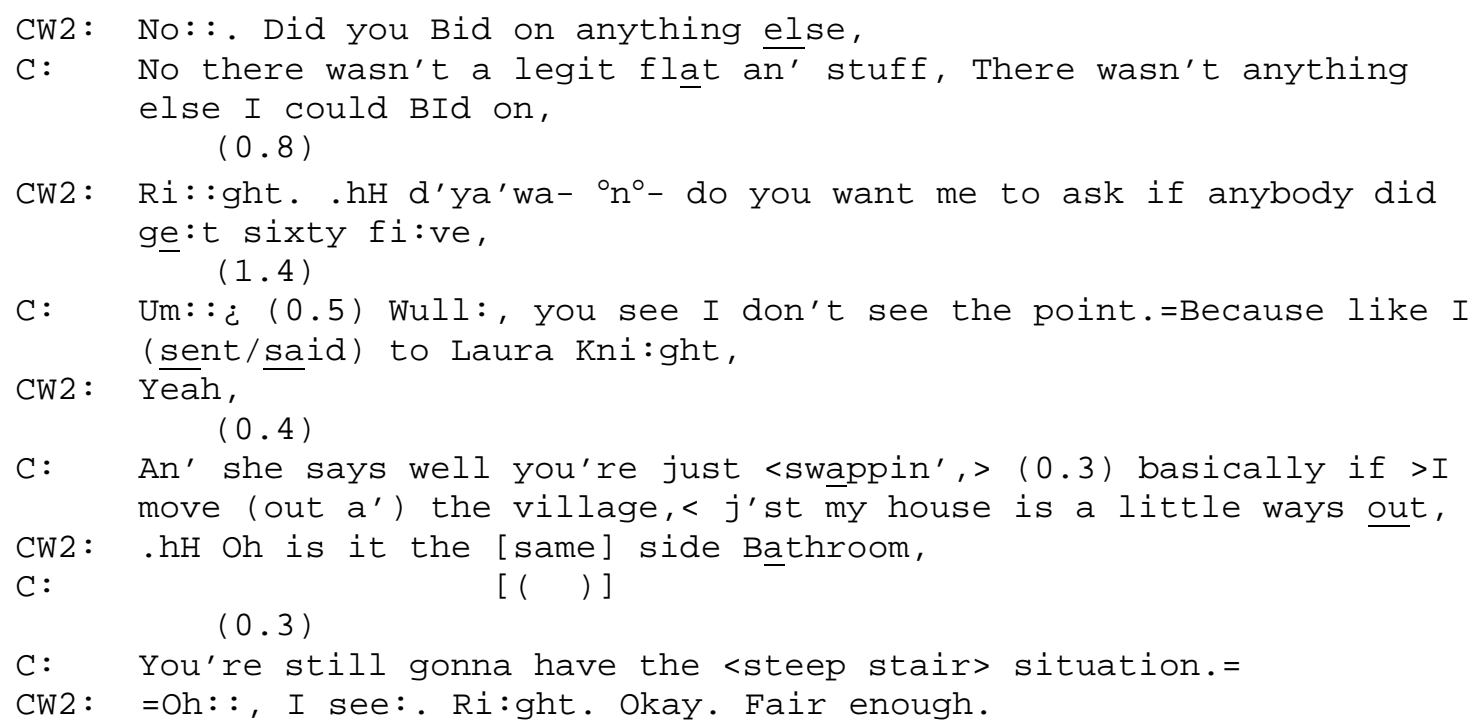

At lines 5-6, CW offers to find out what happened to the house (number 'sixty five') that C wanted to bid on. The offer is based on whether the constituent 'wants' the caseworker to look into the house, and it is also formulated as a question, requiring the constituent to answer, and thereby accept or reject the offer. $\mathrm{C}$ has, therefore, a maximum amount of control over what course of action CW will pursue. The 'do you want' formulation indexes an even 
stronger deontic position for the constituents than the 'can' formulation, although both make acceptance (or rejection) relevant. It would be inappropriate here to use an 'announcement' offer (see below), because the desires of $\mathrm{C}$ are as yet undetermined. Given that bidding was over, an inquiry into who got the house will not help $\mathrm{C}$ get the house, or get some other house in the future. Examples in our data, such as Extract 6, are different from those discussed in Curl (2006), whereby 'do you want...' formats were used exclusively with educed problems (“offers responsive to overt problems are never produced in this way”, p.1274). Not only is C's problem in Extract 6 not educed - as C's housing problem was already known by both parties, as was the issue of C's interest in that specific house - the offer is produced immediately after the original mention of the problem. The different sequential contexts of the offers (in a series, see Schegloff, 2007, and Request-offers below) result in a different offer format. Curl concludes that the reason why the 'do you want' format is avoided with overt problems may be to avoid implicitly accusing the problem-holder as hinting or 'fishing' for aid. She gives an example of 'do you want'-avoidance after an overt problem, out of the Newport Beach data, seen below.

\section{Extract 7 - NBII.4.R: 181-195 (from Curl, 2006)}

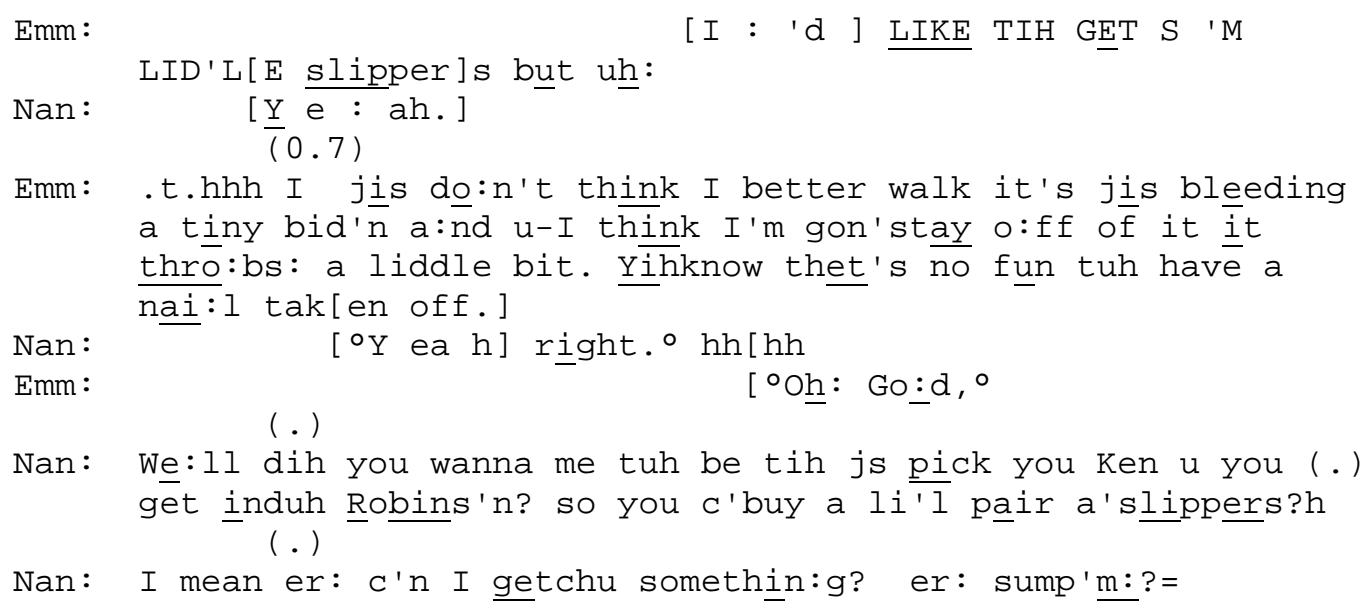

Curl argues that Nancy’s repair from “did you wanna me to” to “can I get you something” (lines 12-15), displays a return to the norm; the norm being to use 'do you want' only with 
educed problems. However, this could be explained more simply: Nancy makes the repair because she already knows that Emma does want something (Emma has just said 'I'd like to get some little slippers’) but is unable to acquire it. Asking “do you want” would amount to asking Emma what Nancy has just been told, and make it appear as though Nancy was not listening. Nancy should know that Emma cannot make use of a mere ride - Emma needs someone to physically get the slippers, because she cannot walk ('I just don't think I better walk it’s just bleeding'). Whether the 'did you wanna' (line 12) was prefacing an offer of a ride or slippers, or any other type of assistance is uncertain, given that Nancy repairs away from that format (the subsequent 'me tuh' cannot grammatically follow 'wanna', implying that self-repair is underway). But any offer here that does not address what Nancy ought to know will be insufficient. In contrast, in Extract 7, CW does not know what C wants, vis-àvis the house bidding. This suggests that educed problem offers may be more about being uncertain of what is offered than about a linguistic norm. For both parties, for CW and for Nancy, there is a social obligation to help the party in need (C and Emma) - Nancy is Emma's sister, and thus may be expected to help her when she is ill, and CW works for an institution where it is in their best interests to help clients in every way possible. Neither is required (by law, ethics, or otherwise) to offer help, and neither turn format could be interpreted as ought but an offer, even outside of the institutional context in Extract 6. This comparison has been drawn to show that knowledge may play a greater role than a norm in determining these turn designs - something that is clearer to see in the institutional context, where the knowledge of $\mathrm{CW}$ is more available to the analyst.

With first time offers, the constituency office as an institution has a more pressing need than a friend or family member might - to be certain that they are acting on the constituents' wishes. Not only do they have a vested interest in acting on the constituents' behalf, in order to best build the 'personal vote' - it is necessary for the staff to get permission from the 
constituents to act on their behalf when dealing with other organizations. First time offers are the first place this permission is sought. This institutional formality hangs in the balance when first time offers are accepted or rejected. As a result, we see this downgraded deontic stance in proposal-offers, as the staff attempt to ensure they are acting on the constituents' wishes.

Note that in both Extracts 6 and 7 above, speakers ask 'do you want me to X', not just “do you want $X$ ”. This is a crucial difference. On the one hand, 'do you want me to $X$ ' gives greater deontic powers to the recipient; the offer is contingent on their acceptance or desire. On the other hand, 'do you want me to $\mathrm{X}$ ' includes a very clear indicator of who must carry out the action on behalf of the recipient. This puts the recipient in a difficult position in terms of a preferred next turn. While offers prefer acceptances (Davidson, 1984), it has been suggested that one should also not burden others with having to do an action (CouperKuhlen, 2014; Clayman \& Heritage, 2014; Kendrick \& Drew, 2014), which creates a crosscutting preference between accepting the offer and not burdening the offerer. In other words, by indicating who must perform the action within the offer turn, the speakers are actually creating a situation in which the preferred next turn may not be acceptance, but rejection. This could be another reason why Nancy repaired away from 'do you want me to', as she may have realized that suggested too high a burden for Emma to accept the offer. These extracts demonstrate one way that constituency offices are more similar to mundane talk than other institutions like doctors’ offices; constituency offices are offering services outside of their mandated institutional purview - they are offering to help constituents, not because it is their job, but because they are doing being 'good' community members and representatives, just as friends and family enact being 'good' friends and family when they undertake offers and actions on behalf of others. One could argue that constituency offices are doing this in order to enact the 'good' representative, whereas family members do it for other reasons 
(such as, they actually like the person they are helping and want to help them). But this would go beyond conversation analysis' capabilities. We cannot say whether the constituency office staff like or do not like constituents, nor whether MPs want or do not want to help citizens. By offering constituency services, and with each offer of service, MPs and constituency office staff enact and re-establish their position as 'good' representatives, partly because of the fact that they offer these services outside of their mandated job roles.

We have seen that at, in the constituency office, first offers of assistance are done using a particular proposal-style design, and made with downgraded deontic stance, indexing that the offer may not be appropriate or acceptable to the constituent. The constituent is expected to respond to these proposal-offers, and response is usually pursued when lacking. In the next section, we consider subsequent offers that relate to courses of action that have already been tried, or are in progress. We will differentiate between offers and explanations of what is offer-able.

\section{Next offers: 'Can' as an Offer vs. 'Can' as an Explanation}

Proposal-offers can appear, grammatically, like explanations of what the office is capable of doing, rather than what it is offering. Both explanations and proposal-offers regularly use the modal verb ‘can' (and its conditional form, ‘could'), and both reference potential future states or courses of action. In real time interaction, however, staff are rarely asked to explain what the office is able to do - constituents usually suss this out more implicitly. Extract 8 below, however, demonstrates the use of 'can', both as an offer, and subsequently as an explanation of the options for courses of action. In the first part of the extract, the constituent has been explaining that he is a small business owner in a residential area, and one resident has been complaining about parking at the business to the local council. The MP for the area is Sarah Johnson. A series of offers is made by the caseworker (CW) in lines 14-17. 


\section{Extract 8 - MP01.Phone-14AH_01: 40-71}

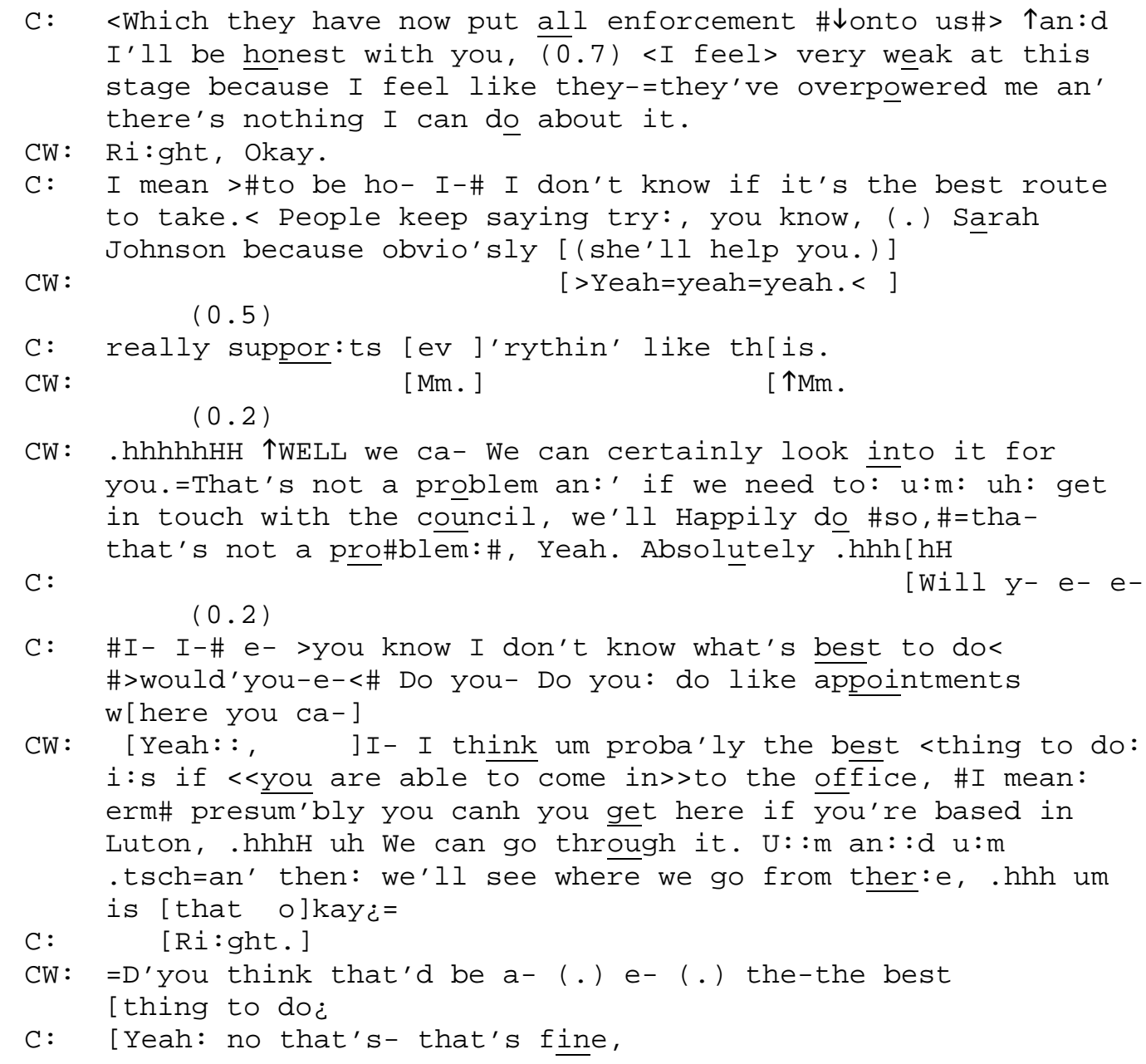

The conclusion of C's problem formulation is that 'people keep saying' he should try contacting the constituency office for help, because he knows that the MP is someone who “really suppor:ts ev’rythin’ like this.” (line 11), which acts as a fishing device (Pomerantz, 1980). The utterance 'people keep saying' constructs a state of knowledge that is widespread, to the general, unnamed people, making it relevant for CW to now explain whether this general knowledge is accurate, what help is available, and whether the constituency office will help $\mathrm{C}$ too. $\mathrm{C}$ also says that he does not know if this is 'the best route to take', something that CW confirms as he begins to describe what the office can do. Note that CW expresses it as something he is 'happy' (line 16) to commit to doing, something that is 'not a problem' 
(line 15 and 17). As in Extract 5 above, in which CW proposed that she "can get a list”, the caseworker here also uses 'can' to formulate the first offer ("We can certainly look into it for you”). In contrast, the second offer uses different format: "if we need to, we'll happily do so" (lines 15-16). Both of these proposal-offers offer a potential future course of action, contingent on the response of the constituent.

But, especially given the context built in the preceding turn, in which $\mathrm{C}$ makes relevant information about what is possible and whether help will be offered, these offers explain the abilities of the constituency office. The relevant acceptance/rejection from C, had they treated them as offers per se, is also missing in the following turn (line 19). Instead, C pursues his own lack of knowledge, saying he does not know 'what's best to do' (line 20), and asks if the office ‘does appointments’ (line 21). This turn does not treat the preceding turn from the caseworker as an offer, but as an insufficient explanation of what the constituency office does. By continuing to reference his own lack of knowledge and pursuing the question of what the office could do next, $\mathrm{C}$ treats his previous fishing device as incomplete or unsatisfied.

As the call unfolds, we can see more evidence that $\mathrm{C}$ does want an explanation of what the office is capable of doing in general. Extract 9 comes after $\mathrm{C}$ and $\mathrm{CW}$ have scheduled the appointment referenced in Extract 8 and CW has given directions to the constituency office.

\section{Extract 9 - MP01.Phone-14AH_01: 170-192}

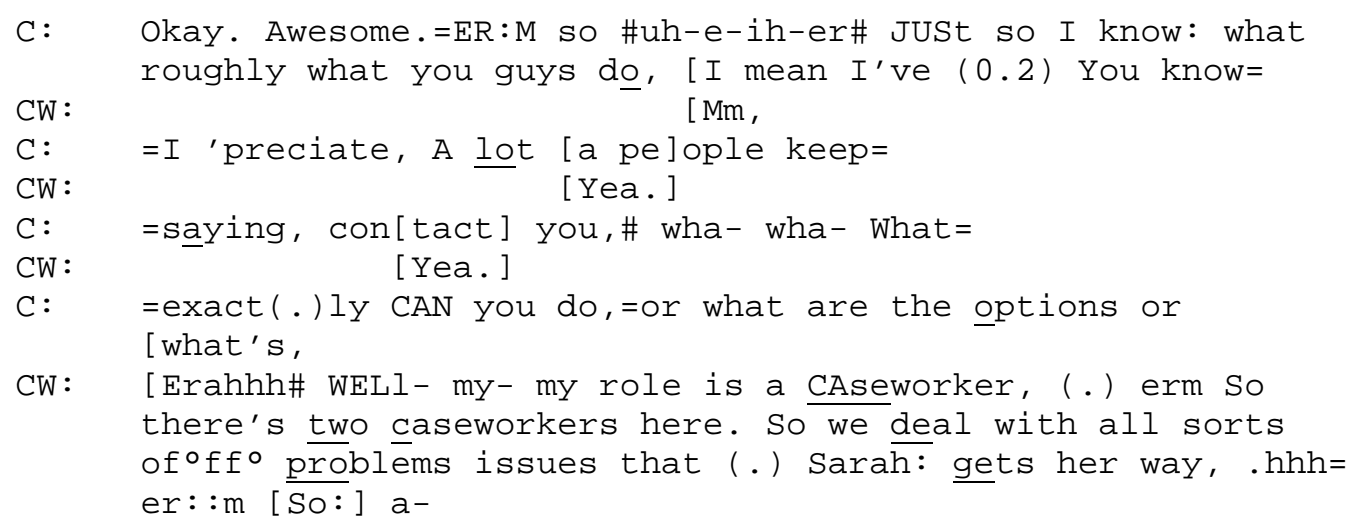




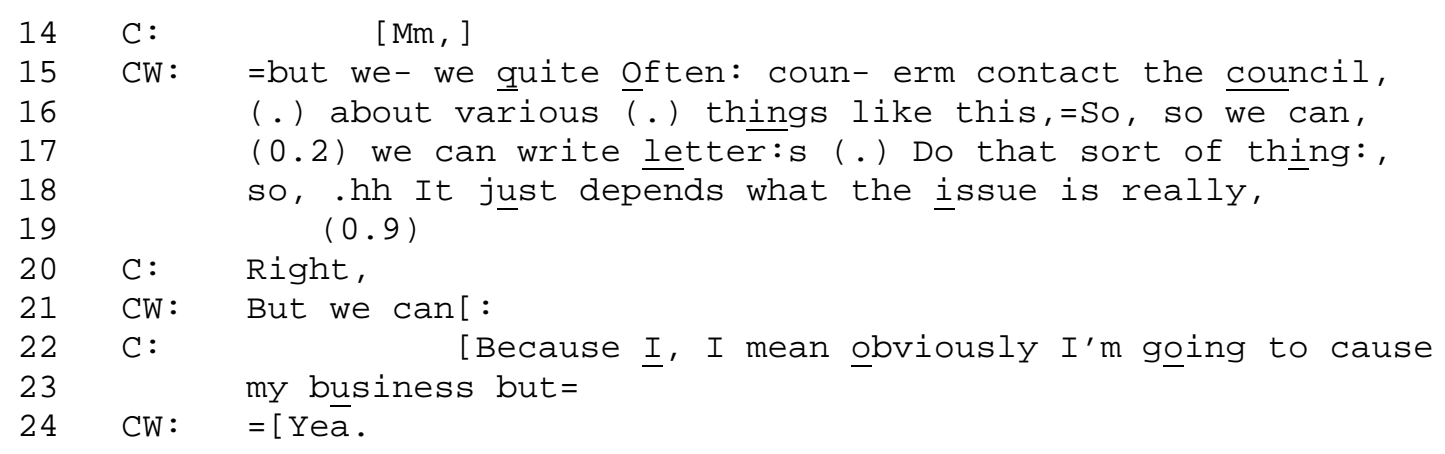

What is the difference between offering a potential course of action, and explaining a potential course of action? In Extract 8, CW explained potential future courses of action, but did so with explicit costs and benefits indexed ('benefactive stance’, Clayman \& Heritage, 2014). CW said that the office would 'look into for you', making it clear that the potential action was for C's benefit. CW also referenced the ease of doing the actions, and the willingness of the office to do the actions, thus indexing a low cost for the office to accomplish this assistance. The sequential and institutional context (as an agency that purports to help constituents) both indicate that the 'can' formulations were offering, not merely explaining, available assistance. In Extract 9, however, CW is responding to a direct question about what the constituency office can do as an organization, instead of a troublestelling, and explains the office’s general abilities, rather than specifically what potential actions could be offered to the client at hand. While the caseworker still uses 'can' (such as in line 15, 'we can write letters'), no benefactive stance is indexed. The explanation is characterized by the use of the present continuous voice, the use of the word 'often' (in line 14, 'we often contact the council'), and the phrase 'sorts of things' (such as in lines 11 and 16), all indicating the general, scripted activities of the office (Edwards, 1994). Extracts 8 and 9 demonstrate how proposal-like designs (especially including the verb 'can') act either as explanations or as components in an offer. By using the 'can' design in turns that are offers, constituency office staff take advantage of this explanatory feature, combining both the offer 
and the explanation of what the constituency office is willing and capable to do for constituents. This implicit 'teaching' of the institutional rules is, as we noted earlier, important at the constituency office, where constituents often display uncertainty about what the constituency office can do. Proposal-offers are thus very useful as first offers at the constituency office, because they simultaneously explain and offer.

In the next section, we consider offers made in the form of announcements, used to repeat offers made earlier, as well as to renew efforts at assistance already underway.

\section{Announcement offers}

Offers made in the form of an announcement ("I will do X”) are declarations of future intent. We found that these offers did not typically make reference to the desires of the constituent nor make a response to confirm the course of action relevant. They were used to repeat already-made offers and to renew efforts to assist a client who had already been receiving or promised help. Announcement-offers were never used to offer a course of action for the first time (again, 'first' refers to the sequence of events in dealing with a specific case, rather than temporally in the interaction). In Extract 10, C has called to follow up on his case (a rat infestation at his council-owned house). $\mathrm{C}$ demonstrates that he is a repeat caller from the way he introduces himself.

\section{Extract 10 - MP01.Phone-13KK_01: 23-40}

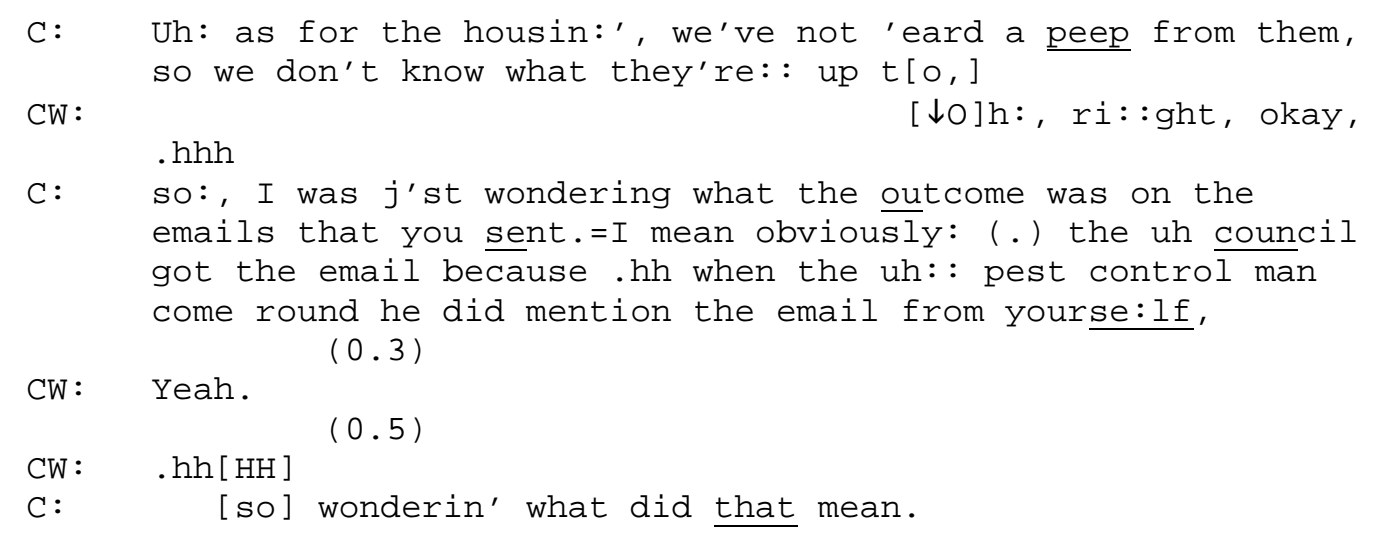


CW: Um: I haven't heard from them $y$ - the: housing people yet so $>I^{\prime} \bar{m}$ afraid sorry about that< I will chase them today::. .hHHH um: : ptk-But-w- HOW's it going though, is it-is it quieter now: can you heār anything:,

$\mathrm{C}$ reports that he has not heard from relevant organizations and wonders if those organizations have spoken to CW instead (lines 3-12). CW responds with an apology that she has not heard from any of the organizations in question, but includes an announcement-offer: 'I will chase them today' (line 14). The offer declares what CW intends to do, including when she will do it. As such, it does not make relevant a response from $\mathrm{C}$ and, indeed, none is forthcoming (line 16). In fact, none of the typical methods of making a response relevant are present. Interrogativity is one way to mobilize a response, but CW produces a declarative statement (Schegloff, 1984; Stivers \& Rossano, 2010). Another way to make a response relevant would be to make the turn a phrase about a B-event (Labov \& Fanshel, 1977), by giving information primarily in the domain of the recipient (e.g., 'you'll want me to call them then') which tends to elicit a response (Pomertanz, 1980; Heritage \& Raymond, 2005; Stivers \& Rossano, 2010). Here, the epistemic domain of the action is constructed as belonging to CW; it is her decision how to run her day, who to chase, and when she will do it. Finally, interrogative format would also make a response relevant, such as making it a yes/no interrogative (Raymond, 2003), but that is not the case either; it is a statement, not a question. So, we are left with the impression that $\mathrm{CW}$ does not expect a response from $\mathrm{C}$, and may even have designed her turn such that the possibility of a response is reduced. However, we are told (Stivers \& Rossano, 2010, p. 5, 26) that, canonically at least, when the action of offering is done, a response is relevant, typically an acceptance or rejection, yet unlike with the offers in the proposal-offer section above, CW does not pursue a response. In summary, there are no features that make a response relevant, no acceptance or rejection is present, and there is no pursuit of a response. Why, then, call these announcements 'offers'? 
Extract 10 fits our definition of an offer in every respect: It displays an implicit benefactive stance - that the 'chasing' that is being promised is for C's benefit and indeed is happening only because $\mathrm{CW}$ has heard nothing and $\mathrm{C}$ is inquiring about the matter. $\mathrm{CW}$ displays that she will be the agent of the activity, and also includes when exactly she will enact this offer. By making an offer, CW portrays the assistance as a logical outcome of the assistance so far not having worked. It shows a strong willingness and ability to offer help, because it is being announced, rather than proposed - it is definite, not potential. It also shows that the office is determined to help; in the face of failure to assist adequately so far, the office may appear to be weak, inept, or not trying hard enough to be of assistance to the constituent. By announcing further assistance (of a kind for which permission has already been granted) immediately in the face of this failure, the office can portray itself as persistent, and reassure the constituent that aid is being pursued in the process.

Announcement offers are not simply declarations of plans (Suchman, 1987) or unilateral decisions (Stevanovic, 2012). They still contain the crucial aspects of an offer - displaying willingness to do an action on behalf of the recipient. Compare, for instance, the following two extracts. In Extract 11, we get a common type of offer (even in non-institutional contexts, when taking messages on a home landline phone): 'I'll take a message for him'. C has been working with one of the two caseworkers, Jason, but Jason is not available that day to take the call. Ann, the other caseworker, offers to take the call. This kind of offer is ubiquitous in telephone conversations, and remains an offer, not an announcement, because of its focus on the willingness of the offerer to do the action.

\section{Extract 11 - MP01.Phone-13KZ2_02: 5-16}

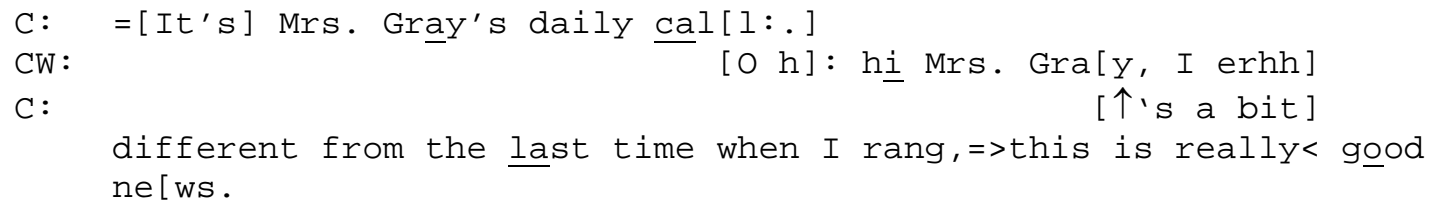




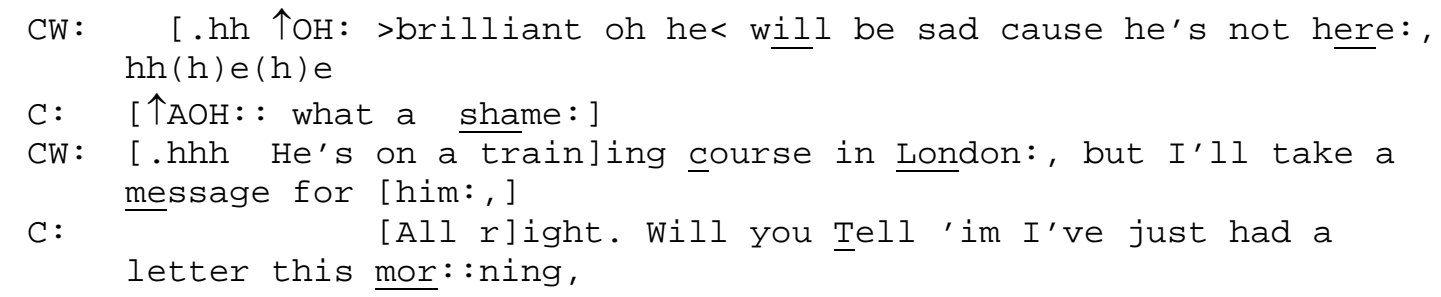

In contrast, Extract 12 is tilted towards making plans.

\section{Extract 12 - MP01.Phone-13KZ_01: 232-239}

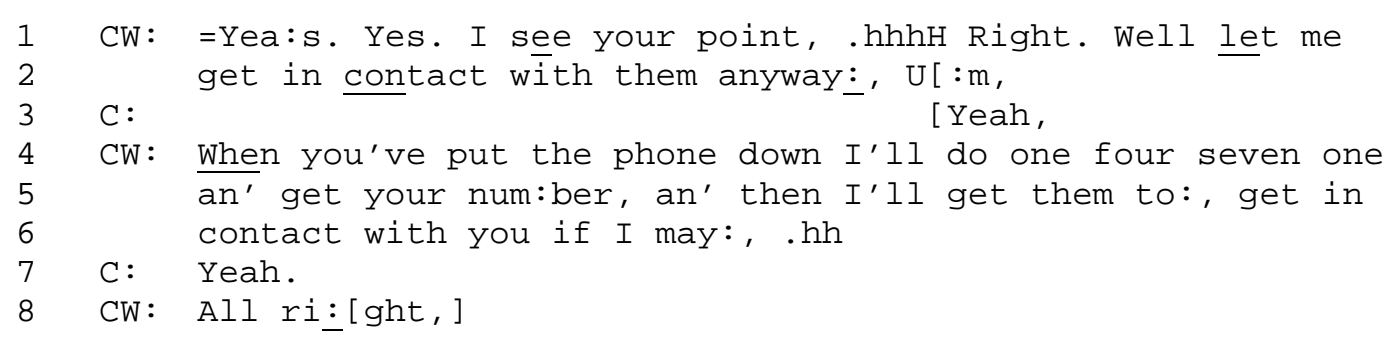

CW says she will do 'one four seven one', which is a way to display the phone number that has just called. CW intends to do this because $\mathrm{C}$ does not know the phone number on which she is calling. In announcing this intention, however, CW is not emphasizing her willingness to do the action, nor the beneficiary nature ( $\mathrm{C}$ does not have to phone back to provide the phone number). Several minutes earlier in the conversation, she requested permission to use ' 1471 ' to get C's phone number, and this utterance confirms that she still intends to do so. In lines 5-6, CW follows up the 'mere' announcement of her intended action (using the 1471 telephone function) with an announcement offer, 'I'll get them to get in contact with you if I may'. This latter statement is more than an announcement; it is an announcement offer, as it indexes CW's willingness to do the action for C, and seeks permission in a tag statement 'if I may’.

Another example of the announcement-offer can be seen in Extract 13. In this conversation, $\mathrm{C}$ has been attempting to schedule an appeal date. Although the difficulty in scheduling is not C's fault, her benefits have been cancelled. This injustice brought $\mathrm{C}$ to the 
surgery, and she was promised to hear back within ten days. The ten days have elapsed without word, so she is calling to see what happened at the constituency office.

\section{Extract 13 - MP01.Phone-13LB_06: 28-66}

C: $\quad$ Hi:, you'al'right?=

CW2: =Yes not too bad.=n'you,

C: Yes fine thank you, .hh um: $s^{\prime} j$ 's wondering if you'd heard anything cause you'd- uh::m I think you spoke to my husband you said (.) hopefully to be able to tell 'im something within ten da:y[s.

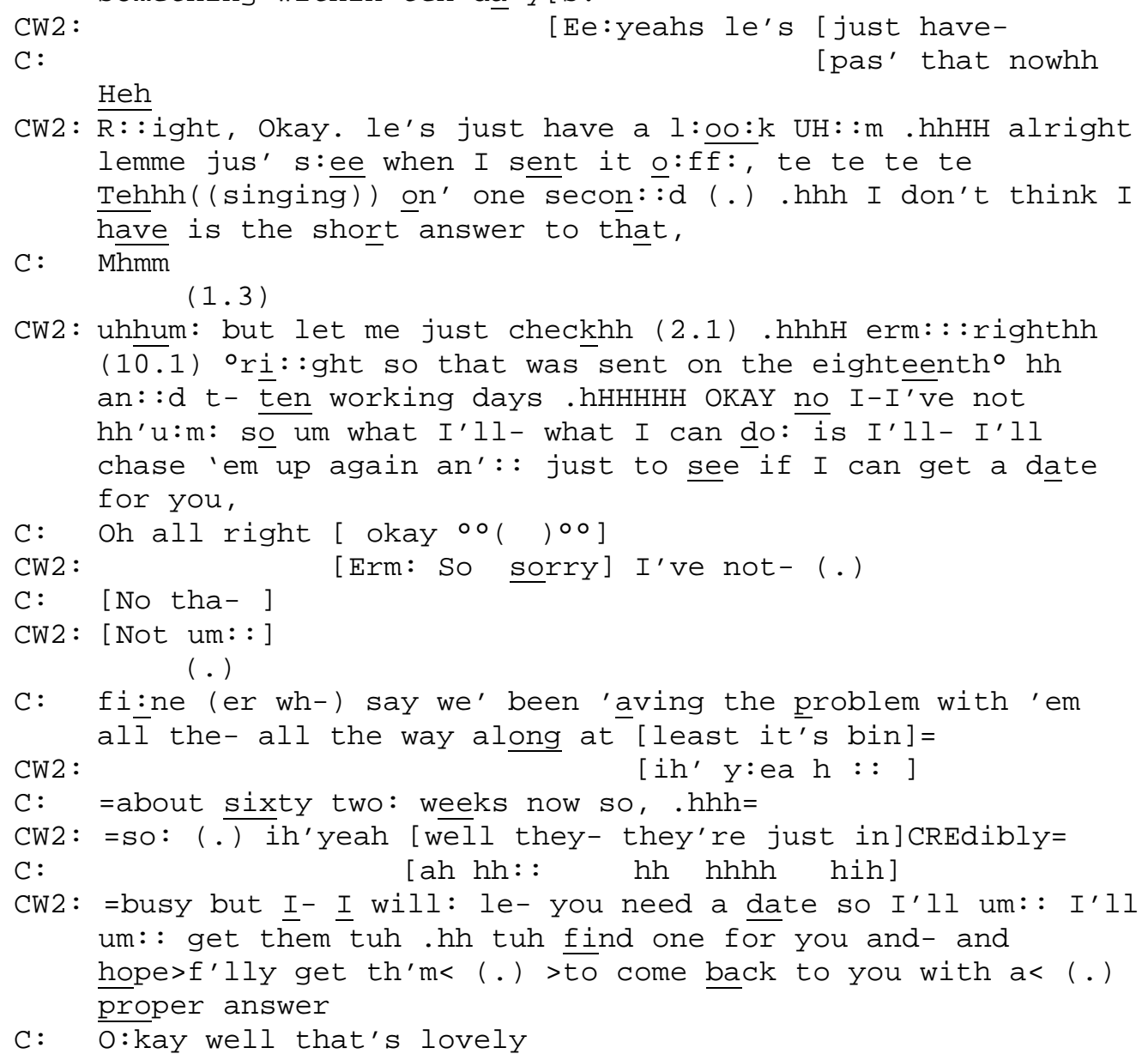

On lines 17-19, the caseworker (CW2) goes through several self-repairs to arrive at an announcement offer, "I'll chase 'em up again”. The self-repairs demonstrate that while CW2 considered phrasing the offer using a 'what I can do' (as well as a separate 'I will' statement), he chose 'I will' as the optimal formulation in this context (and it is repeated in 'I'll get them to find one for you" on lines 31-32). This fits with our previous analysis, as the offer occurs in 
an environment where $\mathrm{CW}$ already knows what the constituent would like, $\mathrm{C}$ knows what the constituency office has committed to doing and what they are capable of doing, and C has given her permission for the constituency office to act. A proposal-offer would be inappropriate, as it would imply that the constituency office has not paid attention to what $\mathrm{C}$ needs them to do. Furthermore, in this instance it would imply that CW had forgotten what he and the MP had committed to doing in the previous interaction with $\mathrm{C}$ - to get the appeals court to fix a proper date for the tribunal. Using an 'I will' statement here helps to portray the office as not only willing but proactive, and reassuring $\mathrm{C}$ of the constituency office’s commitment to their prior offer by reissuing it in a stronger, more definite manner.

Especially in closings, announcement-offers are used to reiterate what has been offered so far, as a way of committing to the plans for assistance that have been set out during the interaction. For example, in Extract 14, CW is just finishing taking down C's phone number.

\section{Extract 14-MP01.Phone-13KS_02: 68-73}

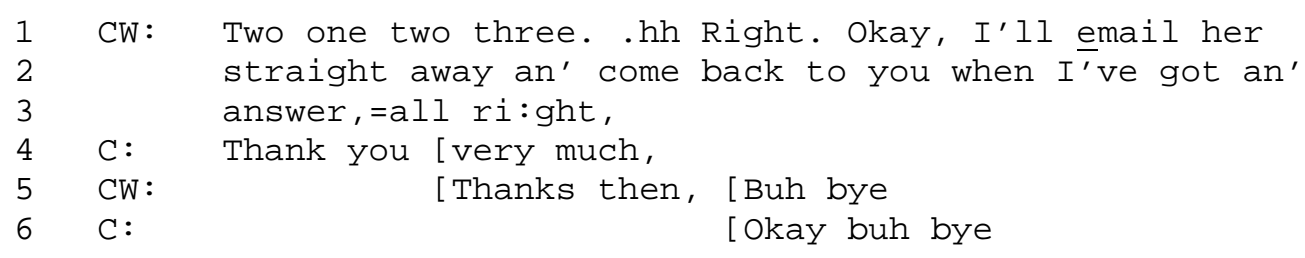

Here, CW initiates closing, and as part of doing so, she repeats the offer that she has already made in this interaction: to email a specific council officer. Most closing portions of calls and surgeries include a component like this one, in which the offer, or offers, that have been given during that interaction are repeated for final evaluation and commitment.

To summarize, in this section we have seen how 'I will' is used to produce announcement-offers, in which the offer is declared as a definite action, not requiring the input or acquiescence of the constituent. They are considered as offers rather than statements 
of planning or intent because of the beneficiary nature for the recipient. These offers are often used when speaking to repeat constituents who have returned to the office with the same problem still active. They are also used during closings to reiterate what the future plans are for the constituent's case. In the final section, we focus on 'request-offers' - the final type we found in the dataset.

Request-Offers: "Let me...”

After proposal-offers and announcement-offers have been made, another offer format occasionally appears, which involves requesting constituents to do (or not to do) something in order that the offer can be fulfilled. The most common way to do this is using the phrase 'let me'. In Extract 15, C has been complaining about a longstanding neighbour dispute. Another agency told him to go and speak with his neighbour but $\mathrm{C}$ is fearful about making an approach.

\section{Extract 15: MP01.Phone-14AE_01: 215-226}

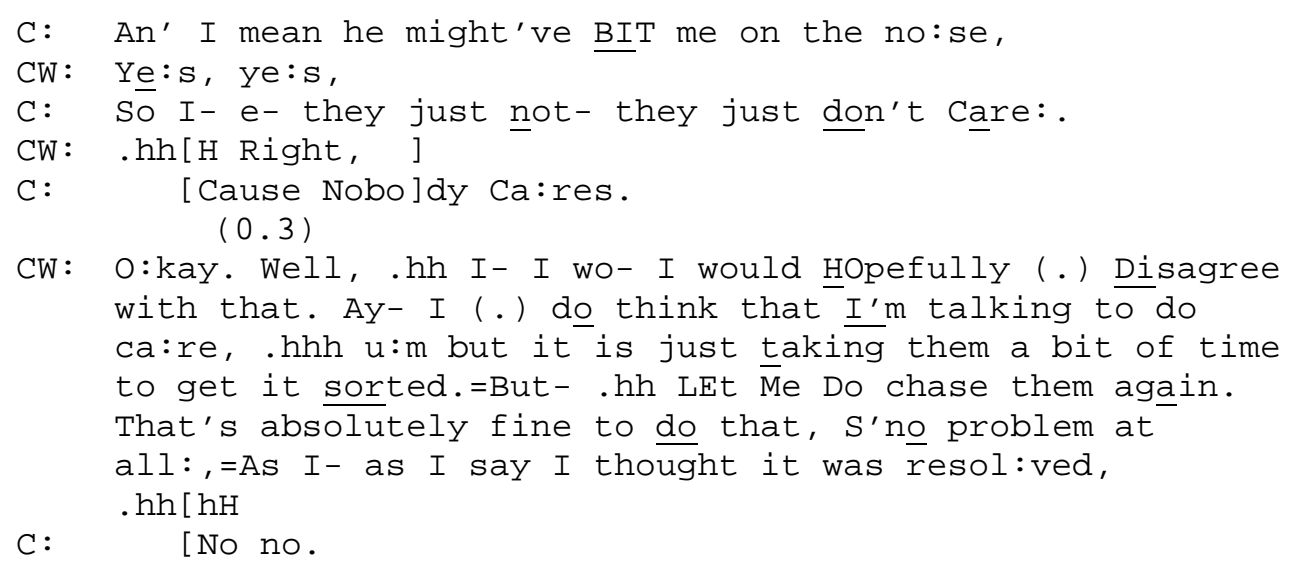

On lines 1-5, C expresses frustration with the agencies he has been dealing with. CW tries to reassure $\mathrm{C}$ that, at least at her end, some people at some agencies 'do care', even if it is taking 'a bit of time' to fix the problem. On line 10, she reissues her offer to track down the relevant 
agencies to try to resolve the problem faster. By using 'let me X', CW formats her turn so that it strongly prefers an acceptance. It not only requests inactivity from $\mathrm{C}$, but promises aid if he says yes. CW mitigates any potential interpretation of burden on lines $11-12$, by saying that it is 'absolutely fine' and 'no problem at all', which further helps reduce the possibility that C will reject the offer.

The formulation 'let me' breaks down the boundary between an offer and a request. On the one hand, 'let me' requests (or even commands) that the constituent do (or rather, not do) something, by issuing a directive. On the other, it proposes to benefit $\mathrm{C}$ by providing assistance. These offers were instrumental in creation the definition set out in the introduction: the beneficiary is largely the constituent, the caseworker is largely one who will enact the offered action, and there is extra work being done here which should not invalidate this turn's basic status as an offer. To understand this extra work, we need to step further back in this phone call. Almost 100 lines earlier than Extract 15, CW makes her initial offer of assistance. By this point in the call, $\mathrm{C}$ has established himself as a repeat client, whose case has continued for over two years without resolution. Besides the frustration that he has expressed about this delay, CW did not remember who he was at the beginning of the call. She has also made it clear that the office does not have the correct information about C's case, and so thought it was already resolved. Once C has corrected CW, the following lines occur.

\section{Extract 16 - MP01.Phone-14AJ_01: 135-176}

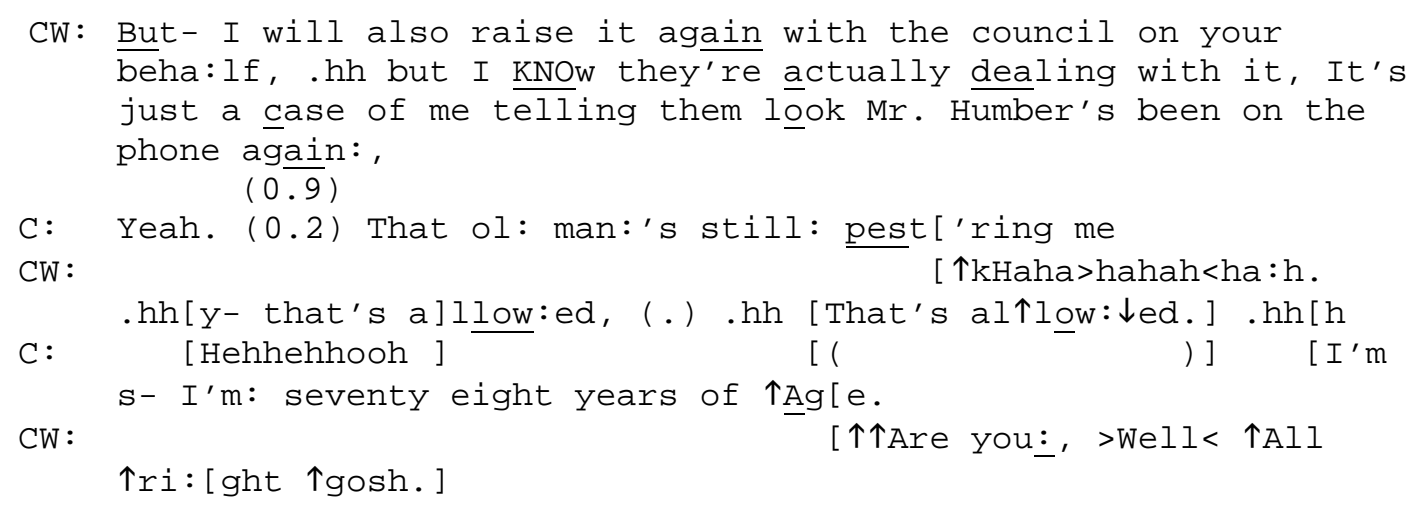


13 C: [(Yeah $\left.\left.\mathrm{an}^{\prime}\right)\right] \mathrm{An}^{\prime}$ I need I: Nee:d.hhh uh-protection.

14 CW: Ye:s. uh- Quite ri:ght.=

$15 \mathrm{C}:=A n^{\prime}$ I pay: $\downarrow$ hundred and $\uparrow$ thirty six pound a month,

16 CW: [Yeah, ]

17 C: [for my] rates, (๑.3) An' I: .hhh [have ]n't (.) gone to the-

18 CW:

$19 \quad(0.3)$

20 C: sstep that I considered, (1.0) <I considered writing $>$ to 'im

21 an' saying "<until you do that> to put it ri:ght, (0.5) I'm not

22 going to pay me ra:tes.

23 CW: Yea-uh-well:: .hhh uh:m: [I wouldn't necessarily ad]vise

$24 \mathrm{C}$

25

On lines 1-2, CW issues the first offer of the call, 'I will also raise it again with the council'. The call has now been established as a repeat call, so the format of 'I will' makes sense, as C's permission has already been sought, and given the frustration C is experiencing, a definite offer is appropriate. In response, $\mathrm{C}$ jokes that he is still chasing this issue, and goes on to make a case for needing assistance: he is elderly, 'needs protection' (line 13), pays his rates (i.e., his rent and taxes), and although he considered not paying his rates in protest (lines 1722), he has not yet taken this drastic step. CW recommends against that idea, and then at line 27, reissues the offer, this time in a 'let me' format. This formulation may be an attempt to 
manage C's expressed frustration. By strongly preferring an acceptance, CW attempts to get C 'on side' with the offered course of action. There is no question of his permission any more, but it is important that he be satisfied with the help he is receiving.

By not accepting the offer in line 1, C displays resistance to the offer. Such resistance has been documented elsewhere, especially in medical interactions (Toerien et al., 2011; Stivers, 2005; Heritage \& Sefi, 1992; Hepburn \& Potter, 2011). In this respect, caseworkers offering courses of action are similar to doctors offering courses of treatment. In both contexts, the client is responsible for accepting or declining the offer, and this response carries the client's permission and 'buy-in' to the suggested process. Here, C displays resistance by not responding to the offer (lines 5 and 6), by continuing to provide arguments for needing assistance despite having been made an offer (lines 9-10, 13, 15-22, and 36), by negatively assessing the work so far (line 24), and by otherwise only giving minimal acknowledgements that something has been said (e.g., line 37) instead of more strongly aligning phrases (see Stivers, 2005). CW, faced with non-aligning turns, makes the offer again, on line 27. The 'let me' formulation can be seen as an attempt to respond to the new arguments for assistance; to suggest that in order to provide help, C needs to let CW get to work, and to more strongly make an acceptance relevant. In Extract 15 above, we can see that CW reissues the 'let me' offer later on in the call. In fact, she does it yet again (in data not shown) before she receives an acceptance, shortly before the end of the call. The 'let me' formulation both manages resistance by strongly preferring an acceptance (almost as if it were a request instead of an offer), and highlights that the 'burden' of the action will be undertaken by the caseworker. This format appears in other calls and meetings as well, but is the least common of the three formats considered in this paper - an unsurprising finding, given that constituents are usually eager to accept any help from the constituency office that is offered. It is only in cases where the office has had significant difficulty in finding an appropriate or successful course of action 
to offer that the 'let me' formulation arises. The 'let me' formulation creates a hybrid scenario: the format of a request, but the action of an offer of assistance.

In this section, we have seen how 'let me' offers blur the boundary between offer and request, as they request that constituents do something (or do nothing) in order to allow an offer to be fulfilled. However, these are still offers because they benefit the recipient, and are enacted by the offerer. These offers are used to help manage constituent resistance to courses of action.

We have not considered in our analysis how these offers form part of a series, such as the kind of action series discussed in Schegloff (2007, pp. 207-215). This is because the offers in our dataset do not consistently belong to a series. A few offers discussed in this paper (Extracts 5, 12, 14, 15, and 16) are part of a series of offers issued by the staff, which move the trajectory of the project of assistance toward a mutually acceptable course of action. Some of these issue new offered actions (such as calling different agencies, or researching different areas), and some involve reissuing the same action (most easily seen in Extracts 15 and 16). This latter version involves switching the format to our 'request offers', as a way of managing resistance. Other extracts show first offers in an interaction, although second or third offers concerning the proposed assistance (Extracts 10 and 13), and there are some that are later in an interaction but first concerning the course of action (Extract 2, 3, 4, 6, 8, and 11), the latter of which all fall into our category of 'proposal offers', since they are first offers of an offered action. Schegloff's series thus overlap with how we characterize the data, but we feel our analysis more accurately and specifically portrays what the offers are accomplishing.

Furthermore, while the series explored in Schegloff (2007) are temporally and sequentially close to each other, many of the offers presented here were related to topics discussed days or weeks prior, albeit by the same participants. Schegloff's offers examples (pp.210-211) Although the speaking roles (who issued the first or second pair part of the 
offer) remained the same (which is due to the institutional nature of the data) over time, it did not seem appropriate to label offers from separate interactions as part of the same series. In future work, we would like to explore the way these topics are repeated across very large expanses of time - something that the constituency office, as an institution, is well suited to analyzing, given how common it is for cases to involve repeated contact over several months.

\section{Conclusion}

In this paper, we have investigated a core aspect of the interaction that occurs between members of the public and their elected representatives - politicians, or Members of Parliament - as well as those caseworkers who support the work of such politicians. It is in such encounters that the work of constituency offices gets done, and we have given what is, to the best of our knowledge, the first empirical analysis of this part of the democratic system. At the same time, we have focused on a core activity of institutional social life; the offers of assistance that people make to one another and some of the related activities that engender such actions. In this way, the paper contributes not only to what we know about politicianpublic interaction, but also a fundamental conversation analytic interest in the actions that are built in institutional encounters and, particularly, offers.

We found that MPs and caseworkers offer to assist their constituents by building three distinct offer formats. Proposal-offers (e.g., 'I can do X for you' and 'do you want') are used to simultaneously indicate what aid is possible and offer that aid as an option. We found that proposal-offers require the constituents' acceptance in order to progress, and are used as the first offer of a course of action. Announcement-offers indicate that a course of action has been decided, and will be enacted. They allow caseworkers and MPs to take up a proactive stance in helping their constituents, and are used to confirm offers that already made. Request-offers 
are a last resort, used when constituents resist an offer. They project a preferred next turn of alignment and/or acceptance, while also dealing with the arguments that constituents have presented. These types of offer work in concert to allow caseworkers and MPs to effectively manage the concerns of their constituents. In the case of 'do you want me to X' offers, the explicit indexing of party responsibility may contribute to conflicting preferences for acceptance or rejection - in the few times it was used, recipients chose to reject it and suggest that there was no need to attempt the offered aid.

We rehearsed the way conversation analysts have previously defined and described offers-in-interaction in the introductory part of the paper. Our empirical observations are most aligned with Couper-Kuhlen (2014)'s definition that offers are proposed actions that benefit the recipient and are carried out by the speaker. However, we have suggested that this is not a clearly demarcated distinction; both parties must take some action, even if it is only providing permission (and, in the case of request-offers, it is sometimes necessary to withhold action, in order for an offer to be completed), and the benefits resulting from an offer can be shared. Furthermore, the turn designs we have reported frequently blur the lines between a prototypical offer and other actions, such as proposals, announcements, and requests (which are often stated to be the polar opposite and dispreferred alternative to offers - see Schegloff, 2007; Kendrick \& Drew, 2014). Therefore, the offers we have analysed support Sacks’ (1992) suggestion that requests, offers, proposals, threats, and so on, should be considered as part of a continuum of possible actions, rather than as opposites, or discrete concepts (see also Sidnell \& Enfield, 2014). Analyzing actions as fluid possibilities, rather than discrete categories, enhances our understanding of how and why participants use different formulations. As Schegloff (1997) writes, "boundary cases are the sparks struck by the collision of two analytic practices” (p.539); making room for grey zones between and among actions demonstrates points at which more interactional work is being accomplished. Considering actions as part of 
a continuum or spectrum will likely prove useful beyond institutional data, as a more flexible conceptualization of action achievement in mundane talk as well.

We can see in this corpus that participants have a use for making offers in several different formats. Proposal-offers allow caseworkers to gather more information about the case, and seek the institutional pre-requisite of permission. Announcement-offers allow caseworkers and politicians to appear proactive and helpful. Request-offers give caseworkers the ability to pursue permission and alignment with constituents. Yet these actions all still remain offers, as indicated by the beneficiary nature of the promised action. They are evidence that participants are not constrained to particular action categories, but use the matrix of options available to the advantage of whatever their communication needs happen to be, and we should take care to allow for the flexibility in action formation that we observe.

\section{Funding Acknowledgement}

This research received no specific grant from any funding agency in the public, commercial, or not-for-profit sectors.

\section{References}

Ågren H, Dahlberg M and Mörk E (2006) Do politicians’ preferences correspond to those of the voters? An investigation of political representation. Public Choice, 130(1-2), 137-162.

Arter D (2011) The Michael Marsh question: How do Finns do constituency service. Parliamentary Affairs, 64(1), 129-152.

Blidook K and Kerby M (2011) Constituency influence on 'constituency members': The adaptability of roles to electoral realities in the Canadian case. The Journal of Legislative Studies 17(3): 327-339.

Butler P and Collins N (2001). Payment on delivery: Recognising constituency service as political marketing. European Journal of Marketing, 35(9/10), 1026-1037.

Cain B, Ferejohn J and Fiorina M (1987) The Personal Vote: Constituency Service and Electoral Independence. Cambridge: Harvard University Press. 
Clayman S and Heritage J (2014) Benefactors and beneficiaries: Benefactive status and stance in the management of offers and requests. In: Drew P and Couper-Kuhlen E (eds) Requesting in Social Interaction. Amsterdam: John Benjamins, pp.xx-xx.

Couper-Kuhlen E (2014) What does grammar tell us about action? Pragmatics 24(3): 623647.

Curl T (2006) Offers of assistance: Constraints on syntactic design. Journal of Pragmatics 38: $1257-1280$.

Curl T and Drew P (2008) Contingency and action: A comparison of two forms of requesting. Research on Language and Social Interaction, 41(2), 129-153.

Dalton RJ (2000) Citizen attitudes and political behaviour. Comparative Political Studies, 33(6/7), 912-940.

Davidson J (1984) Subsequent versions of invitations, offers, requests, and proposals dealing with potential or actual rejection. In: Atkinson, JM (ed) Structures of Social Action: Studies in conversation analysis. Cambridge: Cambridge University Press, pp.102-128.

Drew P and Heritage J (eds) (1992) Talk at work: Interaction in institutional settings. Cambridge: Cambridge University Press.

Dropp K and Peskowitz Z (2012) Electoral security and the provision of constituency service. The Journal of Politics 74(1): 220-234.

Edwards D (2005) Moaning, whinging and laughing: The subjective side of complaints. Discourse Studies 7(1): 5-29.

Fenno R (1978) Home style: House members in their districts. Boston: Little, Brown \& Co.

Hepburn A and Potter J (2011) Designing the recipient: Managing advice resistance in institutional settings. Social Psychology Quarterly 74(2): 216-241.

Heritage J and Raymond G (2005) The terms of agreement: Indexing epistemic authority and subordination in talk-in-interaction. Social Psychology Quarterly 68(1): 15-38.

Heritage J and Sefi S (1992) Dilemmas of advice: Aspects of the delivery and reception of advice in interactions between Health Visitors and first time mothers. In: Drew P and Heritage J (eds) Talk at work: Interaction in institutional settings. Cambridge: Cambridge University Press, pp.359-417.

Hansard Society (2015) Audit of Political Engagement 12: The 2015 Report. London: Hansard Society.

House of Commons Information Office (2013) You and Your MP. Brief Guide. UK: House of Commons.

Kärkkäinen E and Keisanen T (2012) Linguistice and embodied formats for making (concrete) offers. Discourse Studies 14(5): 587-611. 
Kendrick K and Drew P (2014) The putative preference for offers over requests. In: Drew P and Couper-Kuhlen E (eds) Requesting in Social Interaction. Amsterdam: John Benjamins, pp.XX-Xx.

Jackson N and Lilleker D (2011) Microblogging, constituency service, and impression management: UK MPs and the use of Twitter. The Journal of Legislative Studies 17(1): 86105.

Johnston R and Pattie C (2009) MPs' expenditure and general election campaigns: Do incumbents benefit from contacting their constituents? Political Studies, 57(3), 580-591.

Labov W and Fanshel D (1977) Therapeutic discourse: Psychotherapy as conversation. New York: Academic Press.

Le Lidec P (2009) French deputies, their assistants and the uses of staff appropriations: A sociology of political work. Sociologie du travail, 518, e117-e135.

Macleod P (2006) How to organize an effective constituency office. Canadian Parliamentary Review, 2(Spring 2006), 9-12.

Mauss M (1950) The gift: The form and reason for exchange in archaic societies. Translated by Halls WD (1990) New York: W.W. Norton.

Maynard D (1986) Offering and soliciting collaboration in multi-party disputes among children (and other humans). Human Studies 9(2-3): 261-285.

Miller WE and Stokes DE (1963) Constituency influence in Congress. The American Political Science Review, 57(1), 45-56.

Norris P (1997) The puzzle of constituency service. The Journal of Legislative Studies, 3(2), 29-49.

Norton P (1994) The growth of the constituency role of the MP. Parliamentary Affairs, 47(4), 705-720.

Norton P and Wood DM (1993) Back from Westminster: Constituency service by British Members of Parliament. Lexington: The University Press of Kentucky.

Pollner M (1979) Explicative transaction: Making and managing meaning in traffic court. In: Psathas G (ed) Everyday language: Studies in Ethnomethodology. New York: Irvington Press, pp.227-255.

Pomerantz A (1980) Telling my side: 'Limited access' as a ‘fishing' device. Sociological Inquiry 12: 186-198.

Toerien M, Shaw R, Duncan R et al. (2011) Offering patients choices: a pilot study of interactions in the seizure clinic. Epilepsy \& Behavior 20(2): 312-320.

Rawlings R (1990) The MP’s complaints service. The Modern Law Review, 53(1), 22-42. 
Raymond G (2003) Grammar and social organization: Yes/no interrogatives and the structure of responding. American Sociological Review 68(6): 939-967.

Sacks H (1992) Lectures on Conversation. Oxford: Blackwell.

Schegloff EA (1984) On some questions and ambiguities in conversation. In: Drew P and Heritage J (eds) Talk at work: Interaction in institutional settings. Cambridge: Cambridge University Press, pp.28-52.

Schegloff EA (1997) Practices and actions: Boundary cases of other-initiated repair. Discourse Processes 23: 499-545.

Searing D (1994) Westminster’s World. Cambridge: Cambridge University Press.

Sidnell J and Enfield NJ (2014) The ontology of action, in interaction. In: Enfield NJ, Kockelman P and Sidnell J (eds) The Cambridge Handbook of Linguistic Anthropology Cambridge: Cambridge University Press, pp.423-446.

Stevanovic M (2012) Establishing joint decisions in a dyad. Discourse Studies 14(6): 779803.

Stevanovic M and Peräkylä A (2012) Deontic authority in interaction: The right to announce, propose, and decide. Research on Language and Social Interaction 45(3): 297-321.

Stivers T (2005) Non-antibiotic treatment recommendations: delivery formats and implications for parent resistance. Social Science \& Medicine 60(5): 949-964.

Stivers T and Rossano F (2010) Mobilizing response. Research on Language and Social Interaction 43(1): 3-31.

Stokoe E (2012) Moving forward with membership categorization analysis: Methods for systematic analysis. Discourse Studies 14(3): 277-303.

Suchman L (1987) Human-machine reconfigurations: Plans and situated actions. Cambridge: Cambridge University Press.

Wright T (2010) What are MPs for? The Political Quarterly, 81(3), 298-308.

Yiannakis DE (1981) The grateful electorate: Casework and Congressional elections. American Journal of Political Science, 25(3), 568-580. 